\title{
DINAMIKA FUNGSI DAN ORGANISASI RUANG PADA HUNIAN DI KAWASAN SITUS LIYANGAN TEMANGGUNG
}

\author{
Rizki Swandani \\ Mahasiswa Program Magister Jurusan Arsitektur Lingkungan Binaan (ALB) \\ Fakultas Teknik, Universitas Brawijaya, Malang \\ e-mail: sathiswandani@gmail.com \\ Antariksa \\ Dosen Program Magister Jurusan Arsitektur Lingkungan Binaan (ALB) \\ Fakultas Teknik, Universitas Brawijaya, Malang \\ e-mail: antariksa@ub.ac.id \\ Lisa Dwi Wulandari \\ Dosen Program Magister Jurusan Arsitektur Lingkungan Binaan (ALB) \\ Fakultas Teknik, Universitas Brawijaya, Malang \\ e-mail: lisaromansya@ub.ac.id
}

\begin{abstract}
ABSTRAK
Ditemukannya situs kuno Liyangan di kawasan permukiman di Dusun Liyangan, Kabupaten Temaggung berkembang menjadi kawasan pariwisata, kawasan konservasi penelitian dan perdagangan secara tidak langsung menyebabkan (setidaknya) dinamika ruang pada hunian di sekitar situs tersebut. Penelitian ini berbeda dengan penelitian sebelumnya, karena berusaha mendeskripsikan dinamika ruang pada hunian (ranah arsitektural) di kawasan situs purbakala (ranah arkeologi). Metode pengumpulan datanya yaitu: observasi lapangan, wawancara mendalam, dokumentasi, sketsa dan pengukuran arsitektural. Rancangan penelitian berjenis kualitatif, sedangkan strategi penelitian berjenis deskriptif. Menggunakan dua metode analisis yaitu: analisis deskriptif dan analisis komparatif. Temuan pada penelitian ini adalah deskripsi dari dinamika fungsi ruang dan organisasi ruang pada hunian di kawasan situs Liyangan.
\end{abstract}

Kata kunci : situs Liyangan, dinamika fungsi ruang, dinamika organisasi ruang.

\section{ABSTRACT}

The discovery of the ancient Liyangan site in the residential area of Liyangan Hamlet, Temaggung Regency developed into a tourism area, research and trade conservation areas indirectly led to the dynamics of the space around the site. This research is different from previous research, because it seeks to describe the dynamics of space in occupancy (architectural domain) in the area of archaeological sites (archeological domain). The methods of data collection are: field observation, in-depth interviews, documentation, sketches and architectural measurements. The research design was of a qualitative type, while the research strategy was descriptive type. Using two methods of analysis, namely: descriptive analysis and comparative analysis. The findings in this study are the relationship between the dynamics of space functions and the organization of space. 
Keywords: Liyangan site, dynamics of space function, dynamics of space organization.

\section{PENDAHULUAN}

Perubahan suatu lingkungan permukiman tidak terlepas dari terjadinya perubahan di dalam aspek kehidupan. Sedangkan perubahan kehidupan manusia terkait dengan lingkungan fisik, alam dan sosial itu sendiri. Adanya aktivitas baru-pariwisata, kawasan konservasi penelitian dan perdagangan skala luas-pada kawasan yang berdekatan dengan permukiman mengakibatkan terjadinya dinamika terhadap fungsi penggunaan lahan maupun bentukan fisik permukiman yang di kawasan tersebut.

Issue utama yang ada di kawasan penelitian adalah ditemukannya situs kuno Liyangan pada areal penambangan pasir dan pertanian warga yang berdekatan dengan kawasan permukiman di Dusun Liyangan, Kabupaten Temaggung. Dusun Liyangan yang pada awalnya hanya merupakan permukiman di pegunungan berkembang menjadi kawasan penelitian yang bahkan mulai mengarah menjadi kawasan pariwisata sehingga dalam perkembangannya memberikan pengaruh terhadap fungsi penggunaan ruang bagi kehidupan masyarakat di sekitarnya. Dalam perkembangannya, areal bahan tambang galian $\mathrm{C}$ atau tambang pasir tempat diketemukannya Situs Liyangan yang dulu sebagai tempat mata pencaharian warga sekitar saat ini disterilkan menjadi area konservasi situs cagar budaya. Beberapa bentuk pengaruh pada lingkungan dan hunian di sekitarnya dapat diidentifikasi dari masih banyaknya artefak dari penggalian di kawasan Situs Liyangan yang disimpan di rumah-rumah warga sebelum nantinya diamankan oleh BPCB (Badan Pelestarian Cagar Budaya) Jawa tengah. Beberapa rumah warga juga mulai difungsikan sebagai homestay dan fasilitas penunjang (toko, warung makan, toilet umum) untuk mengakomodir keberadaan peneliti dan pengunjung yang ingin mengeksplorasi lebih jauh tentang situs tersebut. Jalan-jalan di dalam permukiman menuju situs diperbaiki aksesnya untuk mempermudah peneliti dan pengunjung yang datang.

Dinamika pola permukiman ini penting diteliti untuk dijadikan bahan referensi dalam pemanfaatan atau penggunaan lahan di kawasan tersebut di waktu mendatang supaya tidak merusak zona konservasi situs mengingat masih banyaknya aretefak yang diprediksi belum tergali oleh para arkeolog. Sehingga nantinya dapat diketahui area-area yang bisa dikembangkan untuk areal terbangun dan non terbangunnya. Dalam penambahan fungsi areal terbangun untuk tujuan mendukung perkembangan kawasan menjadi objek wisata juga perlu diatur dan dibatasi agar tidak menyebabkan degradasi lingkungan pada kawasan mengingat permukiman di Liyangan ini terletak di lereng gunung yang cukup padat, rentan terhadap longsor, 
sehingga membutuhkan ruang terbuka yang memadai sebagai areal resapan air.

Pengembangan kawasan Situs Liyangan memang belum maksimal sebagai objek wisata budaya dan masih terfokus pada areal penelitian arkeologi. Dalam rencana pengembangan pariwisata Kabupaten Temanggung, kawasan ini akan dikembangkan menjadi semacam taman konservasi yang berada satu kesatuan kawasan dengan permukiman, pertanian, dan tradisi penduduk setempat (Sunaryoko, 2017). Sehingga dalam prosesnya diupayakan agar tetap terjalin kualitas hubungan ruang yang selaras dan saling mendukung antara permukiman warga dengan kawasan arkeologis yang dikembangkan menjadi objek wisata budaya.

Unit amatan (variabel) ditentukan kecenderungan dari studi terdahulu tentang: tema sejenis (tema: dinamika); fungsi sejenis (fungsi: permukiman) dan lokasi sejenis (lokasi: Liyangan). Diidentifikasi terdapat empat unit amatan (variabel) yang bersifat kritis berdasarkan studi terdahulu yaitu: (1) dinamika fungsi ruang; (2) dinamika organisasi ruang; (3) dinamika orientasi ruang dan (4) dinamika sirkulasi ruang. Pada penelitian ini dibatasi hanya dua pembahasan yaitu dinamika fungsi ruang dan dinamika organisasi ruang.

\section{TINJAUAN PUSTAKA}

Kajian teori mengenai fungsi ruang diambil berdasarkan konsep dari Altman (1975) dan de Yong \& Tedjokoesoemo (2016). Berdasarkan konsep dari Altman, fungsi dapat dibagi menjadi tiga yaitu: fungsi primer, fungsi sekunder dan fungsi publik (Altman, 1975). Fungsi primer adalah ruang yang sangat penting dan tidak tergantikan, sedangkan fungsi sekunder adalah ruang yang penting namun dapat tergantikan. Berbeda dengan fungsi publik merupakan fungsi umum.

Kajian teori mengenai organisasi ruang diambil berdasarkan konsep dari Bonaita (2015) dan Febrianto (2017), yaitu pusat (center) dan tepi (peripheral). Organisasi pusat ruang didefinisikan sebagai ruang yang memiliki aktivitas utama / primer. Organisasi tepi ruang didefinisikan sebagai ruang yang memiliki aktivitas penunjang / sekunder.

\section{METODE PENELITIAN}

Metode pengumpulan datanya yaitu: observasi lapangan, wawancara mendalam, dokumentasi dan pengukuran arsitektural. Rancangan penelitian berjenis kualitatif, sedangkan strategi penelitian berjenis deskriptif.

Penelitian ini menggunakan strategi penelitian deskriptif, yaitu berusaha untuk menyajikan cerita-cerita dinamika ruang pada hunian di kawasan 
situs Liyangan. Mengapa penelitian ini menggunakan strategi penelitian deskriptif karena beberapa alasan berikut: penelitian ini tidak berusaha untuk "berusaha mengeksplorasi suatu peristiwa, aktivitas, proses atau sekumpulan individu-individu" seperti strategi studi kasus; penelitian ini tidak berusaha untuk "menemukan sesuatu" seperti yang diharapkan pada strategi grounded theory; penelitian ini tidak berusaha berusaha untuk "memahami sesuatu" seperti yang diharapkan pada strategi etnografi; penelitian ini tidak berusaha berusaha untuk "mendeskripsikan pengalaman-pengalaman" seperti yang diharapkan pada strategi fenomenologi (Cresswell, 2012).

Metode analisis datanya yaitu: analisis deskriptif dan analisis komparatif. Analisis deskriptif berusaha mengidentifikasi dinamika fungsi dan organisasi ruang pada masing-masing pada empat (4) kasus studi hunian terpilih (sampel). Analisis komparatif berusaha mengkomparasi empat kasus studi hunian terpilih (sampel) dengan studi terdahulu.

Tabel 1.

Metode penelitian

\begin{tabular}{|c|c|c|c|c|}
\hline No & Variabel & Indikator & $\begin{array}{c}\text { Metode } \\
\text { Pengumpulan } \\
\text { Data }\end{array}$ & Metode Analisis Data \\
\hline 1 & $\begin{array}{l}\text { Fungsi } \\
\text { Ruang }\end{array}$ & $\begin{array}{l}\text { Primer } \\
\text { Sekunder } \\
\text { Tersier }\end{array}$ & \multirow{2}{*}{$\begin{array}{ll}\text { - } & \text { Observasi } \\
& \text { Lapangan } \\
\text { - } & \text { Wawancara } \\
& \text { mendalam } \\
\text { - } & \text { Dokumentasi } \\
& \text { arsitektural } \\
\text { - } & \text { Pengukuran } \\
& \text { arsitektural }\end{array}$} & $\begin{array}{ll} & \text { Analisis Deskriptif (antar } \\
\text { kasus studi terpilih) } \\
\text { - } \quad \begin{array}{l}\text { Analisis Komparatif (dengan } \\
\text { kajian jurnal terdahulu) }\end{array}\end{array}$ \\
\hline 2 & $\begin{array}{l}\text { Organisasi } \\
\text { Ruang }\end{array}$ & $\begin{array}{l}\text { Pusat } \\
\text { Tepi }\end{array}$ & & $\begin{array}{ll}- & \text { Analisis Deskriptif (antar } \\
\text { kasus studi terpilih) } \\
\text { - } \quad \begin{array}{l}\text { Analisis Komparatif (dengan } \\
\text { kajian jurnal terdahulu) }\end{array}\end{array}$ \\
\hline
\end{tabular}

\section{HASIL DAN PEMBAHASAN}

\subsection{Analisis Deskriptif Fungsi Ruang}

Analisis deskriptif berusaha mengidentifikasi dinamika fungsi dan organisasi ruang pada masing-masing pada empat (4) kasus studi hunian terpilih (sampel). Kasus hunian terpilih ke-1 berfungsi sebagai hunian biasa, kasus hunian terpilih ke-2 berfungsi sebagai guest house, kasus hunian terpilih ke-3 berfungsi sebagai rumah toko, kasus hunian terpilih ke-4 berfungsi sebagai hunian penyimpanan benda cagar budaya. Berdasarkan tabel 2, ditemukan bahwa dinamika fungsi ruang pada kasus hunian terpilih ke-1, dinamika fungsi ruang sekunder menjadi ruang primer terjadi pada ruang keluarga. Pada kasus hunian terpilih ke-2, dinamika fungsi ruang sekunder menjadi ruang primer terjadi pada kamar tidur. Pada kasus hunian terpilih ke-3, dinamika fungsi ruang sekunder menjadi ruang primer terjadi pada kamar tidur yang berubah menjadi took. Pada kasus hunian terpilih ke-

PAWON: Jurnal Arsitektur, Nomor I Volume 3, Bulan Januari - Juni Tahun 2019, ISSN 2597-7636 
4, dinamika fungsi ruang sekunder menjadi ruang primer terjadi pada ruang tamu yang berubah menjadi ruang penyimpanan.

Tabel 2.

Analisis deskriptif dinamika fungsi ruang

\begin{tabular}{|l|l|}
\hline No & \multicolumn{1}{c|}{ Deskripsi Naratif } \\
\hline 3 & $\begin{array}{l}\text { Dinamika fungsi ruang terjadi } \\
\text { pada ruang tengah / ruang } \\
\text { keluarga menjadi (sebagai fungsi } \\
\text { sekunder) menjadi ruang primer } \\
\text { untuk menerima tamu. } \\
\text { Ruang tengah berubah berfungsi } \\
\text { untuk rapat bagi pengelola Balai } \\
\text { arkelologi }\end{array}$ \\
\hline 2 & $\begin{array}{l}\text { Dinamika fungsi ruang terjadi } \\
\text { pada kamar tidur. Awalnya kamar } \\
\text { tidur penghuni menjadi kamar } \\
\text { tidur pengelola Balai arkelologi. } \\
\text { Kamar tidur berfungsi sebagai } \\
\text { ruang untuk menginap para } \\
\text { peneliti dari balai arkelologi }\end{array}$ \\
$\begin{array}{l}\text { Tidak terjadi dinamika fungsi } \\
\text { ruang. Namun ruang sekunder } \\
\text { menjadi ruang sekunder terjadi } \\
\text { pada kamar tidur yang berubah } \\
\text { menjadi toko }\end{array}$ \\
$\begin{array}{l}\text { Toko berfungsi sebagai untuk } \\
\text { memenuhi kebutuhan para } \\
\text { peneliti dari balai arkelologi dan } \\
\text { juga wisatawan }\end{array}$ \\
$\begin{array}{l}\text { Dinamika fungsi ruang sekunder } \\
\text { menjadi ruang primer terjadi pada } \\
\text { ruang tamu yang berubah menjadi } \\
\text { ruang penyimpanan } \\
\text { Ruang penyimpanan artefak } \\
\text { berfungsi sebagai ruang untuk } \\
\text { menyimpan artefak dari balai } \\
\text { arkelologi }\end{array}$ \\
\hline
\end{tabular}

\subsection{Analisis Deskriptif Organisasi Ruang}

Analisis deskriptif berusaha mengidentifikasi dinamika fungsi dan organisasi ruang pada masing-masing pada empat (4) kasus studi hunian terpilih (sampel). Kasus hunian terpilih ke-1 berfungsi sebagai hunian biasa, kasus hunian terpilih ke-2 berfungsi sebagai guest house, kasus hunian 
terpilih ke-3 berfungsi sebagai rumah toko, kasus hunian terpilih ke-4 berfungsi sebagai hunian penyimpanan benda cagar budaya.

Pada kasus hunian terpilih ke-1, awalnya pusat ruang terletak pada ruang tamu, sesudahnya dinamika organisasi ruang terjadi pada ruang tengah. Pada kasus hunian terpilih ke-2, awalnya pusat ruang pada ruang tamu dan ruang keluarga, sesudahnya dinamika pusat ruang terjadi pada ruang tengah. Pada kasus hunian terpilih ke-3, awalnya pusat ruang pada ruang tamu dan ruang keluarga, sesudahnya dinamika pusat ruang terjadi pada ruang tengah. Pada kasus hunian terpilih ke-4, awalnya pusat ruang pada ruang tamu dan ruang keluarga, sesudahnya dinamika pusat ruang terjadi pada ruang tengah.

Tabel 3.

Analisis deskriptif dinamika organisasi ruang

\begin{tabular}{|c|c|c|}
\hline No & Deskripsi Gambar & Deskripsi Naratif \\
\hline 1 & & $\begin{array}{l}\text { Awalnya pusat ruang terletak } \\
\text { pada ruang tamu, sesudahnya } \\
\text { dinamika organisasi ruang } \\
\text { terjadi pada ruang tengah. } \\
\text { Ruang tengah dan ruang tamu } \\
\text { berfungsi sebagai ruang untuk } \\
\text { pertemuan peneliti balai } \\
\text { arkelologi }\end{array}$ \\
\hline 2 & & $\begin{array}{l}\text { Awalnya pusat ruang pada } \\
\text { ruang tamu dan ruang } \\
\text { keluarga, sesudahnya } \\
\text { dinamika pusat ruang terjadi } \\
\text { pada ruang tengah. } \\
\\
\text { Ruang tamu berfungsi sebagai } \\
\text { ruang untuk pertemuan } \\
\text { peneliti balai arkelologi, ruang } \\
\text { tengah sebagai pusat kegiatan } \\
\text { keluarga }\end{array}$ \\
\hline 3 & & $\begin{array}{l}\text { Awalnya pusat ruang pada } \\
\text { ruang tamu dan ruang } \\
\text { keluarga, sesudahnya } \\
\text { dinamika pusat ruang terjadi } \\
\text { pada ruang tengah. } \\
\text { Ruang tamu berfungsi sebagai } \\
\text { ruang untuk pertemuan } \\
\text { peneliti balai arkelologi, ruang } \\
\text { tengah sebagai pusat kegiatan } \\
\text { keluarga }\end{array}$ \\
\hline
\end{tabular}

PAWON: Jurnal Arsitektur, Nomor I Volume 3, Bulan Januari - Juni Tahun 2019, ISSN 2597-7636 


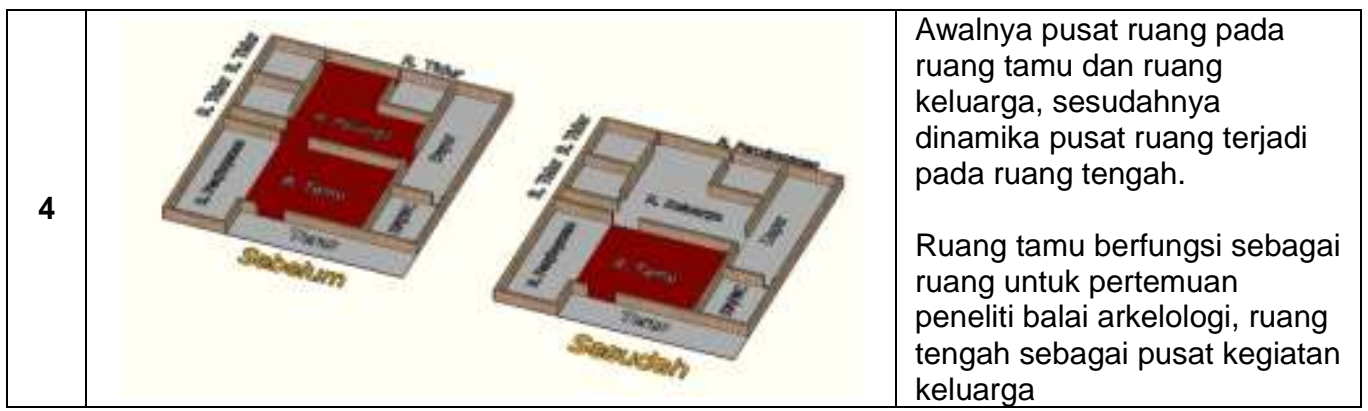

Sumber: Analisis pribadi (2018)

\subsection{Analisis Komparatif dengan Studi Terdahulu}

Analisis komparatif dengan studi terdahulu dideskripsikan Strauss dan Corbin sebagai pembandingan sistematis terhadap dua atau lebih fenomena yang tertampilkan dalam data, baik terhadap gejala-gejala yang dekat atau yang memiliki kesamaan karakteristik tertentu, ataupun terhadap gejala yang dianggap berjauhan atau tidak memiliki karakteristik apapun (Strauss \& Corbin dalam Poerwandari, 2007). Bab ini berusaha mengkomparasikan konsep dinamika fungsi dan organisasi antara hunian situs Liyangan dengan tiga konsep desa yaitu: (1) hunian pada desa wisata (Fajari et al., 2014); (2) hunian berbasis tradisi Jawa (Nurmayanti et al., 2017) dan (3) hunian dekat situs candi.

Fungsi dan organisasi ruang pada hunian di Desa Wisata Bejiharjo, Yogyakarta (Fajari et al., 2014) dimana fungsi primer berada di ruang aktivitas pariwisata dan ruang keluarga, sedangkan organisasi ruang berpusat pada ruang keluarga. Berbeda dengan hunian situs Liyangan yang fungsi primernya berada pada ruang tengah atau ruang keluarga saja, sedangkan organisasi ruang kebanyakan berpusat pada ruang tengah dan ruang tamu.

Fungsi dan organisasi ruang pada hunian berbasis tradisi Jawa Panaragan di Desa Kaponan (Nurmayanti et al., 2017) dimana fungsi primer berada ruang penerima tamu yaitu joglo, sedangkan organisasi ruang kebanyakan berpusat pada ruang tengah dan dapur. Berbeda dengan hunian situs Liyangan yang fungsi primernya berada pada, sedangkan organisasi ruang kebanyakan berpusat pada ruang tengah dan ruang tamu.

Fungsi dan organisasi ruang pada hunian dekat situs Candi Pari Wetan (Ismayana et al., 2014) dimana fungsi primer berada pada ruang tamu, sedangkan organisasi ruang kebanyakan berpusat pada ruang tamu. Berbeda dengan hunian situs Liyangan yang fungsi primernya berada pada ruang tengah dan ruang tamu untuk menerima tamu dari balai arkeologi, sedangkan organisasi ruang kebanyakan berpusat pada ruang tengah dan ruang tamu sebagai ruang berkumpulnya tamu dari balai arkeologi. 


\section{KESIMPULAN}

Dinamika fungsi ruang, terutama ruang sekunder menjadi ruang primer pada masing-masing kasus studi terpilih berbeda-beda. Pada kasus hunian pertama dinamika ruang terjadi pada ruang keluarga dan ruang tamu. Pada kasus hunian kedua dinamika ruang terjadi pada kamar tidur penghuni menjadi ruang tidur peneliti. Pada kasus hunian ketiga dinamika ruang terjadi pada ruang tidur menjadi toko. Pada kasus hunian keempat dinamika ruang terjadi pada ruang tamu menjadi ruang penyimpanan artefak. Dinamika organisasi ruang pada empat kasus hunian terpilih memiliki kesamaan, yaitu dinamika organisasi ruang terletak pada ruang tamu sebagai pusat kegiatan penelitian

\section{DAFTAR PUSTAKA}

Altman, I. (1975). The Environment and Social Behavior. CA: Wadsworth.

Bonaita, Lia. (2015). The Center-Periphery Theories in a Socio-spatial Dimension: A Case Study of the National Museum of Kenya. (Tesis). MilanoBicocca: Universitas Degli Studi.

Cresswell, J. (2012). Eduactional Research: Planning, Conducting, and Evaluating Quantitative and Qualitative Research. Ney Jersey: Person Education, Inc.

De Yong, Sherly., Tedjokoesoemo, Purnama Esa Dora. (2016). Territoriality Concept for Crime Prevention in Interior Design. The Social Sciences Medwell Journals. Vol.11 (No. 15). Pp. 3808-3813.

Fajari, S. R., Suprapti, A., \& Supriyadi, B. (2014). Pengaruh Aktivitas Penunjang Wisata Terhadap Perubahan Tata Ruang Desa Dan Tata Ruang Rumah Tinggal Studi Kasus: Desa Wisata Bejiharjo, Yogyakarta. Jurnal Tesa Arsitektur, Vol 12( No 2), 114-128.

Febrianto, Redi Sigit. (2017). Teritori Ruang Pada Lanskap-Hunian Masyarakat Peladang Desa Juruan Laok Madura Timur. (Tesis). Universitas Brawijaya, Malang.

Ismayana, I. K., Nugroho, A. M., \& Ernawati, J. (2014). Aspek Kekerabatan Dan Budaya Terhadap Pembentukan Permukiman Dusun Candi Pari Wetan Kecamatan Porong, Kabupaten Sidoarjo. Jurnal Perspektif Arsitektur, Vol. 9 (No.2), 115-126.

Nurmayanti, Y., Wulandari, L. D., \& Nugroho, A. M. (2017). Dinamika Spasial Rumah Jawa Panaragan di Desa Kaponan. Jurnal Lengkau Betang, Vol.4 (No.1), 31-43.

Poerwandari, Kristi. (2007). Pendekatan Kualitatif untuk Penelitian Perilaku Manusia. Perfecta LPSP3 Fakultas Psikologi UI: Depok, Indonesia. 